\title{
Leading Indicators of Currency Crises: Discriminant Function Analysis vs. Early Warning Signal Approach
}

\author{
Serpil Kahraman ${ }^{*}$, Görkem Ataman² \\ 1*Department of Economics, Yasar University, İzmir, Turkey, Serpil.kahraman@yasar.edu.tr; \\ ${ }^{2}$ Department of Business Administration, Yasar University, İzmir, Turkey, \\ gorkem.ataman@yasar.edu.tr
}

\begin{abstract}
Money markets play a key role in macroeconomic stability. This study aims to extend discriminant function analysis as early warning models to detect the signaling indicators of the currency crises in developing countries for the period between 1987 and 2007. The obtained model based on these nine countries' data is then tested in different countries set including six developing countries. The theoretical premise of the paper is based on the three-generation currency crisis models. The empirical findings indicate that Current Account Balance/Reserves, M2growth (annual \%), Domestic credit provided by banking sector (\%of GDP), bank liquid reserves to bank assets ratio (\%), GDP annual growth, are the leading indicators of currency crises. The model provided by DFA has around $60 \%$ accuracy in foreseeing the status of crisis in the test data set. The results suggest that discriminant function analysis would be a useful tool to predict the "signal".
\end{abstract}

Keywords: currency crisis, discriminant function analysis, currency crisis index, emerging market economies, early warning signal approach. 